\title{
Integrated Education of Data Analytics and Information Security through Cross-Curricular Activities
}

\author{
Xiao Luo, Connie Justice \\ Department of Computer Information Technology \\ Purdue School of Engineering and Technology \\ IUPUI \\ Indianapolis, USA \\ 1uo25@iupui.edu, cjustice@iupui.edu
}

\author{
Brandon Herald Sorge \\ Department of Technical Communication and Leadership \\ Purdue School of Engineering and Technology \\ IUPUI \\ Indianapolis, USA \\ bsorge@iupui.edu
}

\begin{abstract}
The National Research Council's report states that "cross-sectional studies of multiple courses within a discipline, or all courses in a major, would enhance the understanding of how people learn the concepts, practices, and ways of thinking of science and engineering and the nature and development of expertise in a discipline." In science and engineering, everevolving technology and information make integrative abilities necessary and especially valuable. In this study, we investigated cross-curricular pedagogy, by engaging undergraduate students of two disciplines in collaboration on a common, contextconnected project, so that students are better prepared for solving interdisciplinary problems in career settings. We implemented cross-curricular pedagogy in a network security course and a big data analytics course. The era of big data enables datadriven malicious detection, and big data analytics techniques have been applied to analyzing network logs to reinforce information security and predict abnormal behaviors, so these domains overlap. We investigated two forms of cross-curricular activities: one was integrated instructional units, and the other was crosscurricular knowledge integration projects. The results show significant improvements in students' confidence in solving crossdisciplinary problems and a much better understanding of data analytics and information security, as well as the connections between them. This project is the first to study the loose integration of two context-connected courses that are taught in parallel.
\end{abstract}

Index Terms-Cross-Curricular pedagogy, IT education, knowledge integration, interdisciplinary problem solving

\section{INTRODUCTION}

Many STEM departments in institutions in the United States have academic concentrations as focus points for students' undergraduate studies. The Department of Computer Information Technology (CIT) at our institute has four concentrations: Networking Systems, Information Security, Web Development and Data Management. These concentrations serve as sub-disciplines of the major discipline. By choosing a concentration, students can dive deep into a sub-discipline. Undergraduate students are expected to focus on one or more of the concentrations in their junior and senior years by taking corresponding upper-level courses. Most of the classes are designed to be sub-discipline specific and have different learning outcomes. Hence, they are not intended to be integrated, although some of them reinforce, connect, or intersect with each other. Today, technology and information are transforming knowledge practices, making integrative abilities increasingly necessary and valuable [1].

Figure 1 provides the current curriculum design of two concentrations in CIT at our institute: Information Security and Data Management. Most of the CIT 10000- and CIT 20000level courses are core courses for all undergraduates in the CIT major. So, some of the classes are cross-listed for both concentrations. For example, CIT 20700 Data Communications and CIT 20300 Information Security Fundamentals are core courses of both information security and data management concentrations. These lower-level undergraduate courses are used to prepare students for upper-level courses. CIT 30000and CIT 40000-level courses are advanced courses in the concentrations where students learn advanced technologies, modeling, analysis and problem-solving skills related to the specific domain. Some of the 30000 and 40000 courses are correlated and can reinforce each other context wise. Kalantzis et al. [2] addressed that with the acceleration of the CIT technologies, the boundaries of academic or scientific disciplines are blurring and new disciplines and sub-disciplines are emerging at the borders of the old ones. For example, the era of big data enables data-driven malicious detection. Big data analytic techniques have been applied to analyzing network $\log$ s to reinforce information security and predict criminal behaviors. This overlap of different domains, network security and big data analytics, suggests connections between course CIT 45100 IT Risk Assessment and course CIT 49900 Big Data Analytics. Cross-curricular units of instruction will teach students from different concentrations how concepts and practices are connected between each discipline.

In this study, we proposed to investigate cross-curricular pedagogy for integrated learning of two computer information technology courses in two sub-disciplines: data management and information security, which were context connected and taught in parallel in the same semester. Our objectives for this 


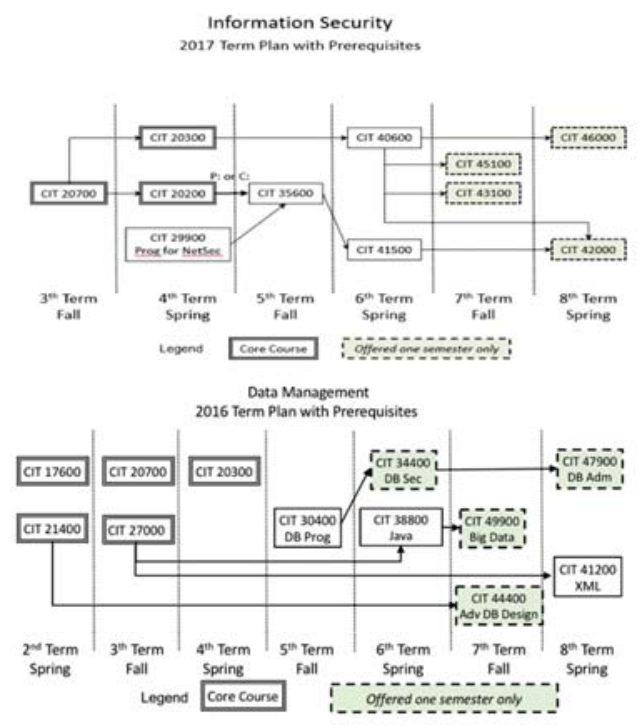

Fig. 1. Undergraduate Courses Plan for Information Security and Data Management

project are (1) to enhance undergraduate students' capabilities to connect and transfer knowledge from one setting to another, by using the integrated curriculum, (2) to improve undergraduate students' expertise in one subject by reinforcing learning through cross-curricular projects and (3) to facilitate students' grasp of the big picture of computer information technology.

The proposed study contributes to developing effective instructional units across two context-connected courses taught in parallel, and designing discipline or sub-discipline integration stimulated projects for two groups of students in two context-connected courses in the same semester. This study also contributes to the national need for an advanced understanding of how people connect and transfer knowledge from one subject domain to another, and how they apply concepts to solve an interdisciplinary problem collaboratively. The success of this loosely integrated learning model will provide a framework, and methods from any two cross disciplines (or sub-disciplines) of STEM, if these disciplines are context connected.

\section{BACKGROUND AND LITERATURE REVIEW}

The National Research Council's report [3] stated that significant changes are required to undergraduate science and engineering education to prepare a diverse technical workforce and science-literate citizenry. The Council recommended that "More investigations are needed of teaching and learning across multiple courses in a discipline," and it also states that "cross-sectional studies of multiple courses within a discipline, or all courses in a major, would enhance the understanding of how people learn the concepts, practices, and ways of thinking of science and engineering and the nature and development of expertise in a discipline." Many studies in pedagogy focused on methods applied to a single course, for example, in- class peer discussion to enhance understanding [4], flipped (inverted) classroom instruction [5], Problem-Based-Learning (PBL) classroom instruction [6], and research-based instruction [6].

The National Research Council's report [3] also recommended interdisciplinary studies of cross-cutting concepts and cognitive processes to enhance students' learning, promote knowledge transfer from one setting to another and better model the real-world STEM problem-solving processes. Heil et al. [7] investigated the integrated STEM education for $\mathrm{K}-12$. There is no precise definition of integrated STEM education. Hence, they used a range of terms to search the scholarly work including: integrated curriculum, crossdisciplinary, multi-disciplinary, project-based and so on. Indeed, integrated STEM education is taking hold of both K-12 and postsecondary education. In STEM 2026 [8], it states that "integrated STEM teaching and learning experiences are incorporated throughout the P-20 continuum.". However, STEM integration has had less of a presence in undergraduate STEM education [9]. Whiteacre et al. [10] explored an integrated freshman engineering curriculum for pre-calculus students at Texas A\&M University in 1996. This curriculum showed the integration of material across the freshman classes. Most of the existing research focused on tight integration of two or more concepts from different STEM disciplines into one course [10], [11], or integration of two or more courses in tandem [13] [12]. Laboy-Rush [14] presented the advantages of project-based STEM integration. Callahan et al. [15] emphasized the needs of the integrated curriculum and defined the integrated STEM model in five levels ( 0 to 4$)$, which involve three general areas: faculty engagement, STEM curriculum and university leadership/systems.

The tightly integrated learning pedagogy to integrate connected concepts into one curriculum might be a better fit for the lower-level undergraduate courses. Most upper-level undergraduate courses are discipline or sub-discipline specific. They are designed to prepare students to be experts in their particular discipline. Tight integration might cause the learner to lose the depth of the course content. Loose integration in the forms of unit-based cross-curricular instruction and collaborative projects are more desired. The literature has suggested that integrated and cross-curricular instruction enable students to see knowledge as connected rather than as individual, isolated subjects [16]. In the real world, the disciplines and sub-disciplines in STEM are connected. Crosscurricular instruction and projects will better prepare students for solving interdisciplinary problems in career settings and will equip them with sustainable skills for life-long learning.

This cross-curricular pedagogy study also aligns with the strategic initiative our institute: "promote Undergraduate Student Learning and Success." Additionally, this study will create linkages between the theory of in-class learning in two separate courses to real-world projects designed to enhance students' capability to transform knowledge from one setting to another. Finally, this cross-curricular pedagogy will also provide undergraduate students with research experience 
across different subject domains.

\section{Cross-Curricular EduCATION Design}

Through this study, we designed and developed crosscurricular activities for two courses (IT Risk Assessment and Big data Analytics) that are context-connected and taught in the same semester. The objective is to use these CrossCurricular activities to enhance student's capabilities in connecting knowledge from multiple settings, and facilitate students' grasp of the big picture in information technology. The cross-curricular activities include (1) cross-curricular instruction units for the context-connected course components to assist students in connecting knowledge from one setting to another; (2) cross-curricular projects to reinforce students' cross-discipline problem solving and research capabilities.

\section{A. Cross-Curricular Integrated Instructional Unit}

Traditionally, the two courses are taught by different instructors and have their own set of learning outcomes. In this study, we first revisited the learning outcomes and identified one or more inter-connected learning outcomes in both courses. Then, integrated instruction units were designed to flesh out the specific outcomes of the context-connected topics of the two courses. Through these integrated units, we encouraged students to connect knowledge from one subject to another based on the context connections. Two specific courses, CIT 45100 IT Risk Assessment and CIT 49900 Big Data Analytics, were used in this study. Table I demonstrates the textbooks, course outcomes and topics for two courses that are connected. When defining an information security strategy and architecture, often related data analytic tools need to be evaluated based on the organization's resource and plan. Hence, the instructional unit was designed to have two groups of students work together to investigate the data analytic tool based on organizational resources and information security strategic plans.

We implemented two delivery formats of the integrated instructional units: joint in-class instruction and joint peerreviewed presentations. The joint in-class instruction is based on the example-oriented approach proposed by Beckmann [16], where examples related to the connected topics of the two courses are explored, with students led by the instructor(s) in the same class. The joint peer-reviewed presentation is a problem-solving approach proposed by Beckmann [16]. Students from courses have expert knowledge in their subject domain, but not the other, so they will need to do some research on the other subject domain and present the solutions based on their perceptions of knowledge. The peer-review part will let students of the two classes provide feedback to each other, and rethink their answers from a systematic point of view. The process will also engage students in critical reflection that helps them articulate questions, confront bias, identify systemic issues and transfer knowledge. Figure 2 demonstrates how in-class instruction and peer-reviewed presentation is organized for the two courses. Before the crosscurricular instruction unit, students of both classes were given an investigation task that they needed to work on individually and prepare solutions for. The task given here was to research on data-driven IT risk assessment tools for an organization. Students of both classes came up with their answers. As shown in Figure 2, there were overlapping solutions from the students of both classes. However, most of the solutions from the students of CIT 49900 were different from those that CIT 45100 students came up with. This is because they used different domain knowledge to select the tools. After students finished identifying the solutions, the cross-curricular unit was organized by the instructor to go through the objective of the task and some main evaluation points from both IT risk assessment and big data analytics points of view. Within the cross-curricular unit, students were then organized into groups to find the best solutions based on their understanding and research. The students in each group were a mixture of students from both classes. In the end, each group delivered a peer-viewed presentation to demonstrate their findings and solutions.

The integrated unit happened towards the second half of the semester. The first half of the semester, students of each course dove deep into their subjects and accumulated fundamental knowledge for developing, integrating, and transferring capabilities.

\section{B. Cross-Curricular Knowledge Integration Oriented Projects based on Inquiry Levels}

In STEM education, hands-on teaching is one of the most effective methods of instruction [17]. Otis [18] discovered five main benefits from the use of hands-on instruction in STEM education include developing students' critical and problem-solving skills and access to materials and programs used in a job in real experience. Rockland et al. stated: "the use of practical, hands-on applications of mathematical and scientific concepts across various engineering topics will help students to link scientific concepts with technology, problem-solving, and design, and to apply classroom lessons to real-life problems." [19] In this project, we designed and implemented cross-curricular projects to give student handson experiences in connecting and reinforcing knowledge in the two disciplines. The hypothesis is that these hands-on projects will enhance students' cross-discipline problem-solving skills, as well as research experiences and capabilities, by connecting knowledge in two subjects.

The cross-curricular projects were designed based on topics that have context connections between two courses. We developed projects based on two inquiry levels that were initially proposed by Schwab [20]. These inquiry levels have been used to evaluate the course-integrated undergraduate research experiences in STEM education as well [21]. In our study, we employed a similar approach to evaluate cross-discipline knowledge transferring skills, along with research experiences and capabilities. Table II shows the inquiry levels. As the inquiry level increases, students' responsibilities increase and instructors' responsibilities decrease. We investigated whether the students involved in different inquiry level cross-curricular 
TABLE I

Course Outcomes And Context-Connected Topics

\begin{tabular}{|l|l|l|l|}
\hline & Textbook & Context-Connected Topics & Corresponding Course Outcomes \\
\hline $\begin{array}{l}\text { CIT 45100 } \\
\text { IT Risk Assessment }\end{array}$ & $\begin{array}{l}\text { Information Security Risk Assessment } \\
\text { Toolkit: Practical Assessments through } \\
\text { Data Collection and Data Analysis } \\
\text { (Mark Talabis, 2012) }\end{array}$ & $\begin{array}{l}\bullet \text { Security Management Models and Practices } \\
\bullet \text { Protection Mechanisms }\end{array}$ & $\begin{array}{l}\bullet \text { Define an information security } \\
\text { strategy and architecture } \\
\text { a Plan for and respond to intruders } \\
\text { in an information system }\end{array}$ \\
\hline $\begin{array}{l}\text { CIT 49900 } \\
\text { Big Data Analytics }\end{array}$ & $\begin{array}{l}\text { Mining of Massive Datasets } \\
\text { (Leskovec, Rajaraman \& Ullman, 2012) }\end{array}$ & $\begin{array}{l}\bullet \text { Design of Data Analytics Models and Process } \\
\bullet \text { Tools and practice for big data analytics } \\
\text { Data Mining: Concepts and Techniques } \\
\text { (Han, Kamber \& Pei, 2011) }\end{array}$ & $\begin{array}{l}\bullet \text { Assess the existing data analytics } \\
\text { appropriate ones based on the } \\
\text { organization's resource and plan } \\
\text { Design state of the art data } \\
\text { analytics techniques to apply to } \\
\text { practical work and research }\end{array}$ \\
\hline
\end{tabular}

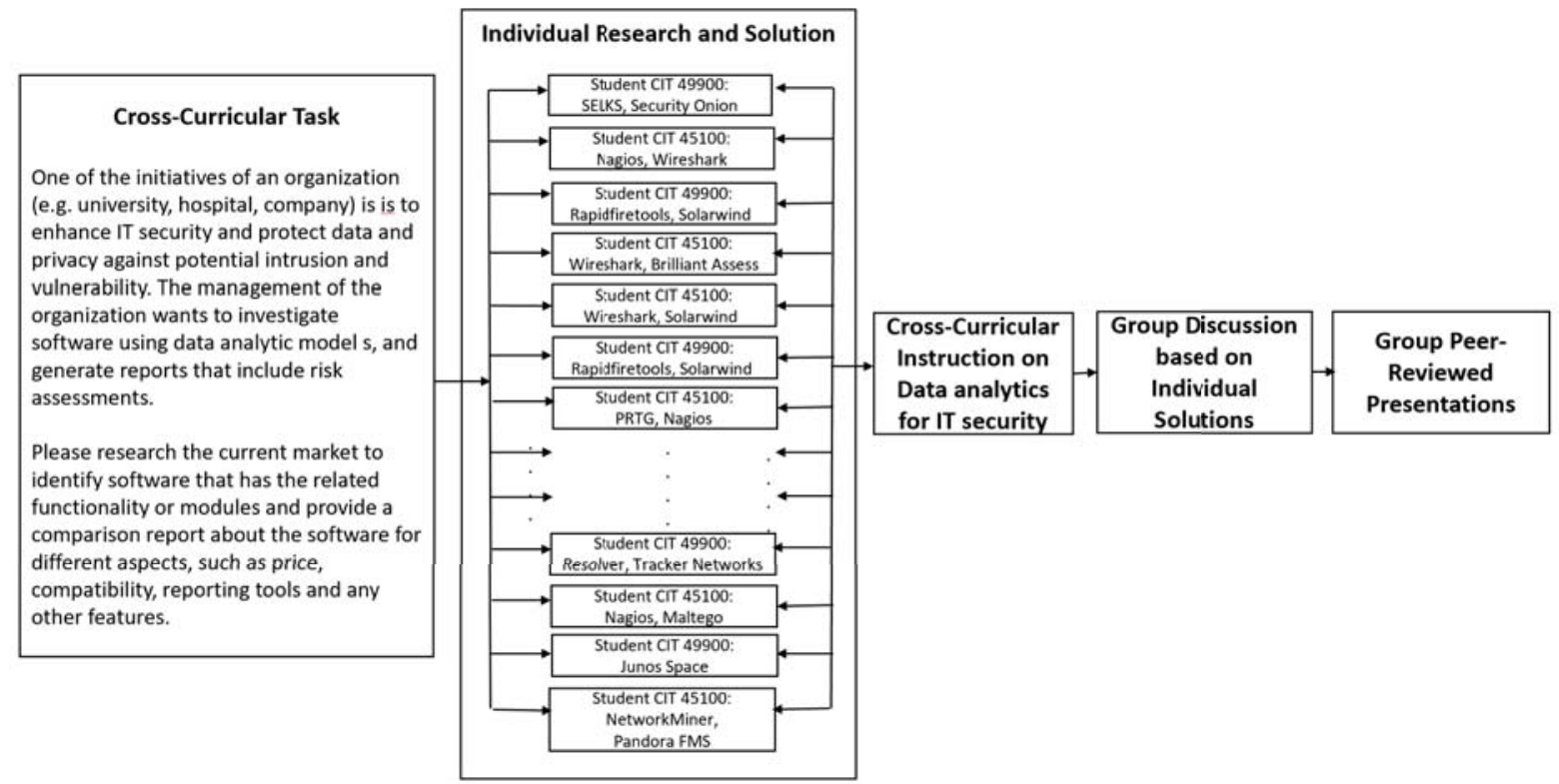

Fig. 2. Implementation of Cross-Curricular Integrated Instructional Unit

TABLE II

INQUIRY LEVELS FOR CROSS-CURRICULAR PROJECTS DESIGN

\begin{tabular}{|c|c|c|c|}
\hline Inquiry Level & Project Problem & Data collection & Expected Results \\
\hline Level 1 & Given by instructor & Given by instructor & Given by instructor \\
\hline Level 2 & Given by instructor & Open to students & Open to students \\
\hline
\end{tabular}

projects differ in cognitive assessments of connecting and transferring knowledge from one subject to another.

The inquiry level 1 project needs a minimum inquiry. Since the students of the two context-connected courses firstly learn knowledge of each subject in the two classes, they might initially be less capable of effectively conducting research and solving cross-discipline problems without any inquiries. For a level 1 project, students are provided with a specific problem, data and expected results. For a level 2 project, students are also provided with a specific problem, but they collect the data and formulate expected results themselves. Students are organized as groups to work collaboratively to identify methods and processes for solving the problem. Figure 3 shows the steps for implementation of the crosscurricular project. The designed project in this study is to have students of two courses work together on implementing a datadriven network intrusion detector. Students were organized into groups. Each group had students from both classes. They needed to work together to finish the project and present their findings at the end. There were four tasks involved: network flow collection, network flow feature selection, data analytics method selection and result interpretation and presentation. All the steps for the level 1 inquiry project were guided by the instructors through written instructions or in-class discussion, 


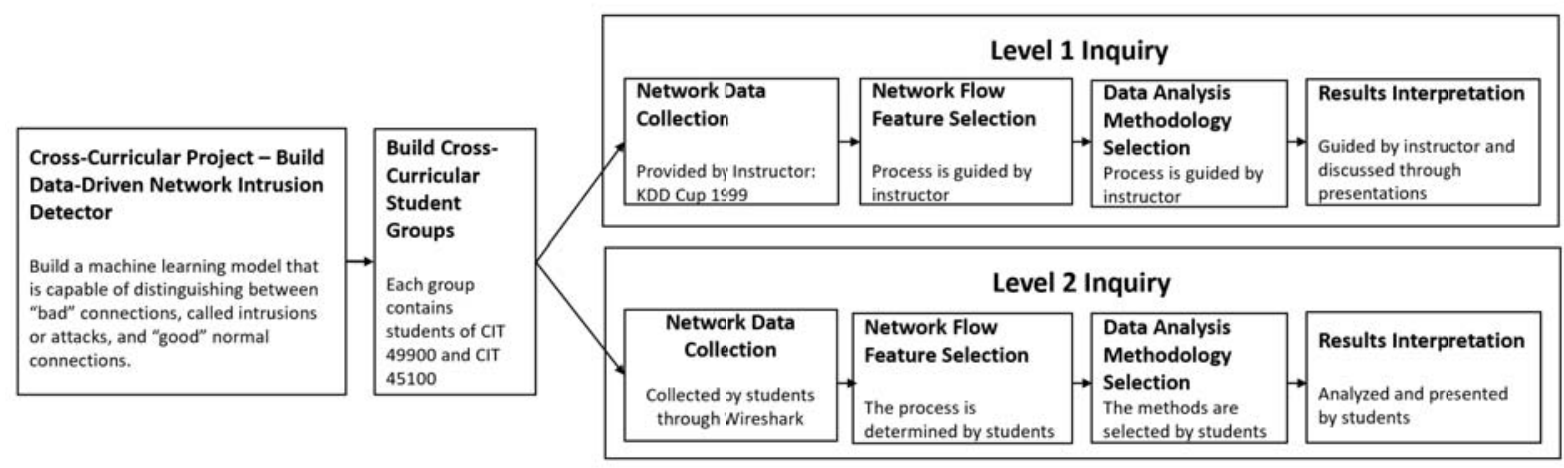

Fig. 3. Implementation of Cross-Curricular Knowledge Integration Project

whereas the actions of the level 2 inquiry project were mostly determined and done by the students. Students had the freedom to choose whatever methods they learned in class to collect network data, analyze data and build the intrusion detector.

\section{Student SuRVEy DESIGN}

The cross-curricular units and projects implementation were administered during the Fall 2017 and Fall 2018 sessions. During the two sessions, an Institutional Review Board-approved before-course survey and an exit survey were conducted to determine the students' knowledge gained in the subject domain of the two courses, as well as improvement of the learning skills in general. Level 1 inquiry projects were implemented in Fall 2017; whereas level 2 inquiry projects were implemented in Fall 2018.

Survey questions were designed to evaluate the knowledge learned in each of the two courses, students' learning skills and impact of the course. These are self-evaluation survey questions. Table III shows the survey questions included in the study. The questions in the category 'Information Security (IS)', 'Data Analytics (DA)' and '21st Century Student Learning Skills' were asked before and after the implementation of the cross-curricular setting of the two courses, whereas the questions in the category 'Impact of the cross-curricular setting' were asked by the end of the semester. Students answered the questions using the following score categories: Strongly Agree (7), Agree (6), Somewhat Agree (5), Neither Agree nor Disagree (4), Somewhat Disagree (3), Disagree (2), and Strongly Disagree (1).

\section{Results And Discussion}

\section{A. Student Survey Results}

In this paper, we show the results of implementation of cross-curricular activities for the Fall 2018 semester. There were a total of fourteen students in the CIT 45100 course and seven students in the CIT 49900 course who took the surveys. Figure 4 shows the percentage of students who scored Strongly Agree and Agree for the pre- and post-surveys for the IS and DA questions listed in Table III. These questions were used to evaluate the students' understanding of the content of each course and the context connections between these two courses. The results showed that students from both classes had significant improvements in understanding the material of each course. We also summed the total student scores for all questions for the pre- and post- survey based upon the numbers provided for each response. A paired samples t-test was run comparing the pre- and post-findings for each group. The mean values of the Information Security (IS) questions for CIT 45100 and CIT 49900 students increased 9.0 and 5.8, respectively, and the mean values of the Data Analytics (DA) questions for CIT 45100 and CIT 49900 students increased 8.5 and 12.1, respectively. It demonstrates that the CIT 45100 students learned more in the IT risk assessment domain, whereas CIT 49900 students learned more in the big data analytics domain. Based on the results of survey questions: IS-c, IS-h, DA-a, DA-c, DA-e, DA-h, which evaluated the students' understanding the connections between two subjects and capability of applying knowledge from one subject domain to another, students from both courses demonstrated significant improvements. Some questions, such as IS-d and IS-g, are designed specifically for the content of information security course, hence, CIT 49900 students show no improvement on these two questions.

Figure 5 shows the percentage of students who rated Strongly Agree and Agree for the pre- and post-surveys for the '21st Century student learning skills' questions listed in Table III. Some items did not show significant improvements; however, we did notice that more students rated Strongly Agree than Agree on those questions. This result demonstrated that through the cross-curricular experience, students' skills in teamwork, communication and time management improved.

Figure 6 shows the students' answers to the questions of 'Impact of the cross-curricular setting.' Through these three questions, we wanted to understand whether the crosscurricular setting was beneficial for their career and and if the setup of the cross-curricular assignment was effective. The results show that over $70 \%$ of students from both courses agree that the cross-curricular environment prepared them better for a career collaborating with others. More than $60 \%$ of students from the CIT 45100 course would like to take more cross- 
TABLE III

Student Self-evaluation SuRvey Questions

\begin{tabular}{|c|c|}
\hline Survey Question Category & Question \\
\hline Information Security (IS) & $\begin{array}{l}\text { a. I am knowledgeable about IT risk assessment. } \\
\text { b. I understand where to gather network traffic data for IT risk assessment. } \\
\text { c. I can explain the data elements/features of network traffic data. } \\
\text { d. I understand how to conduct a risk assessment on network data. } \\
\text { e. I am knowledgeable in IT risk assessment tools that involve data analytics. } \\
\text { f. There is a context connection between IT risk assessment and other IT domains. } \\
\text { g. I understand how to find vulnerabilities from data content. } \\
\text { h. I understand how to create a risk profile. }\end{array}$ \\
\hline Data Analytics (DA) & $\begin{array}{l}\text { a. There is a connection between big data analytics and IT risk assessment. } \\
\text { b. I am knowledgeable in big data analytics. } \\
\text { c. I can apply data analytics to any application domain, such as IT risk analysis and assessment. } \\
\text { d. I can prepare and clean the data according to the requirements, e.g. IT risk assessment. } \\
\text { e. I can explain the data analytics model to an IT network management group. } \\
\text { f. I understand the data analytics life cycle. } \\
\text { g. I can choose the data analytics model based on the requirements given. } \\
\text { h. There is a context connection between data analytics and other IT domains. }\end{array}$ \\
\hline 21st Century Student Learning Skills & $\begin{array}{l}\text { a. I am confident I can lead others to accomplish a goal. } \\
\text { b. I am confident I can encourage others to do their best. } \\
\text { c. I am confident I can produce high quality work. } \\
\text { d. I am confident I can respect the differences of my peers. } \\
\text { e. I am confident I can help my peers. } \\
\text { f. I am confident I can include others' perspectives when making decisions. } \\
\text { g. I am confident that I can make changes when things do not go as planned. } \\
\text { h. I am confident I can work well with students from different backgrounds. } \\
\text { i. I am confident I can manage my time wisely when working on my own. }\end{array}$ \\
\hline Impact of the cross-curricular setting & $\begin{array}{l}\text { a. I feel this cross-curricular course helped to prepare me for a future career collaborating with others. } \\
\text { b. I would take more cross-curricular courses if they were offered. } \\
\text { c. This course helped me understand the connections between big data and information security. }\end{array}$ \\
\hline
\end{tabular}

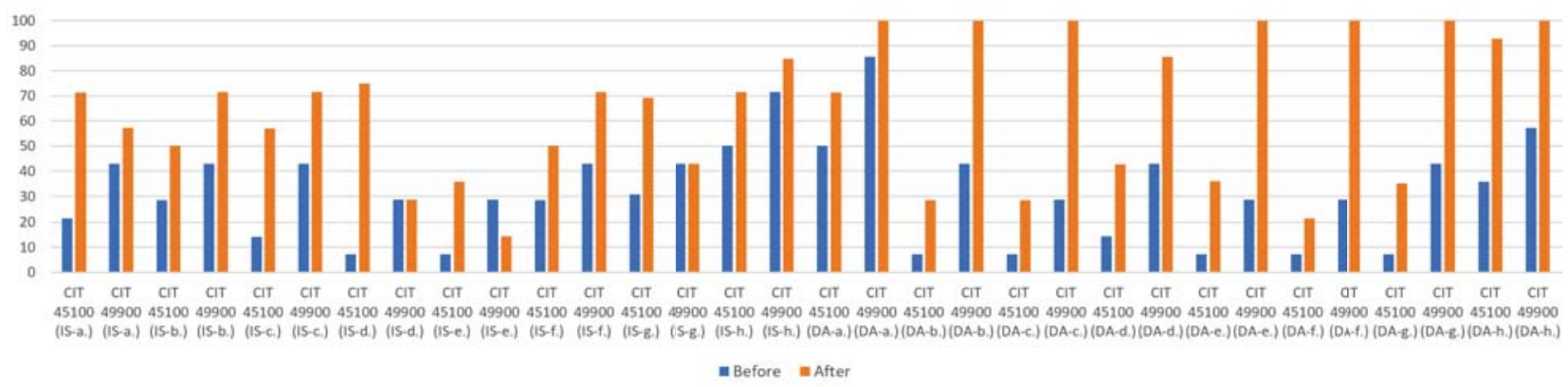

Fig. 4. Survey Strongly Agree and Agree Percentages for IS and DA domains

curricular courses, and more than $70 \%$ of students from the CIT 45100 course and $100 \%$ of students from CIT 49900 course agreed that the course helped them understand the connections between big data and information security, which was one of our primary objectives. We also noticed that only $42.9 \%$ of students from the CIT 49900 course would like to retake the course under the cross-curricular setting. We thought one of the reasons could be that the settings of the crosscurricular project trends towards a heavier workload for the CIT 49900 students. A more balanced workload for students of two courses needs to be considered for the future design of the cross-curricular projects.

\section{B. Feedback from the Cross-Curricular Presentations}

Through the cross-curricular presentations, each group of students presented all implemented tasks and came to an intrusion detection model and conclusion. Figure 7 represents a typical intrusion detection model of a group.

At the end of the presentation, each group was asked questions regarding their cross-curricular experiences. Students' feedback was mostly positive. We also received excellent suggestions from students on how to improve the crosscurricular setting for equal involvement for both courses. For example, instead of using an existing data set, security concentration students can collect real network traffic data by setting up specific tools. Also, many students expressed their interests in testing their intrusion detection model in a real environment. Table IV shows the feedback we received during the presentations.

We also found that some groups even thought about how to create a real-world intrusion detection system by using the data analytics model. It was not required, however, it demonstrated 


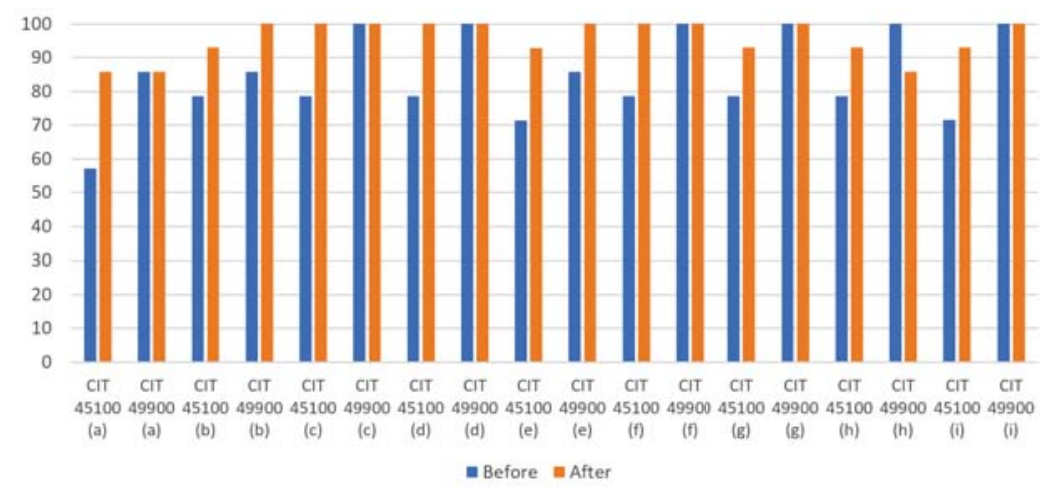

Fig. 5. Survey Strongly Agree and Agree Percentages for 21st Century Student Learning Skills

TABLE IV

STUdENT FEEDBACK FROM THE INTERVIEW

\begin{tabular}{l|l}
\hline Areas & Student Comments \\
\hline Subject Domain Knowledge & $\begin{array}{l}\text { "By inter-joining these disciplines, a complete data model was able to be constructed to } \\
\text { accurately predict and interpret network traffic data." } \\
\text { "We learned a lot from each other, data modeling, data analysis... } \\
\text { "We learned how to create a IDS using machine learning. " } \\
\text { "We will be excited to see if we can plug in our tool to capture the real network traffic. } \\
\text { "Work with the IT risk assessment students, I learned a lot of network terms, } \\
\text { what everything does, etc. It is very interesting." } \\
\text { "Both fields benefit each other." }\end{array}$ \\
$\begin{array}{l}\text { "We prefer we set up the server and collect the network traffic ourselves instead of using an existing data set." } \\
\text { "As network concentration students, we would also want to compare some of the results we can collect from } \\
\text { existing tools with the data model built by big data analytics students." } \\
\text { "It is also to see how we can make use of the detector we created." } \\
\text { "It is good to see how big data analytics interact with another IT field." } \\
\text { "We want to do another final project that we can use data we generate." } \\
\text { "As a future security analyst, we learned how to watch network traffic. } \\
\text { Now, we learned how to create these tools." }\end{array}$ \\
\hline Career Impact
\end{tabular}

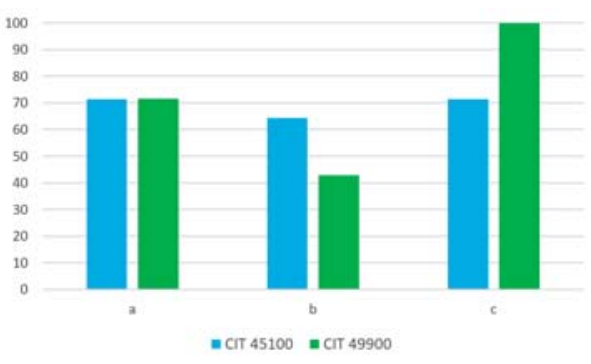

Fig. 6. Impact of the Cross-Curricular Setting

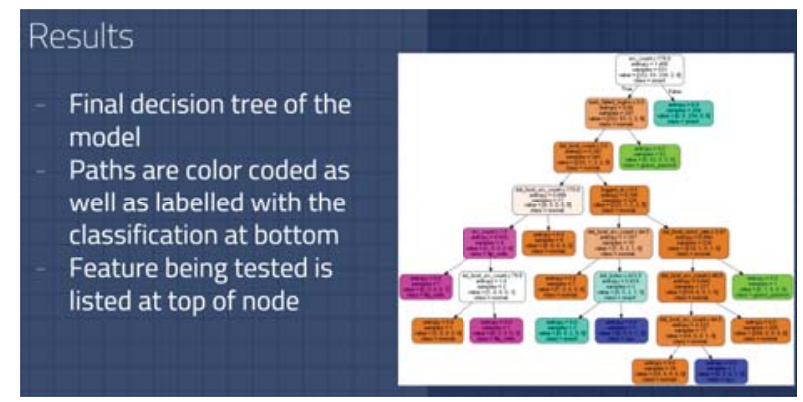

Fig. 7. Typical Intrusion Detector Model the forward thinking of our students and the power of working together. Figure 8 shows the work-flow of a proposed realworld intrusion detection system proposed by one group.

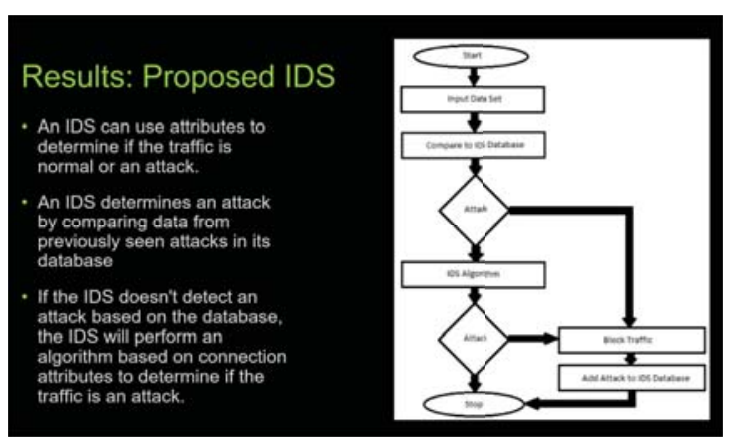

Fig. 8. Proposed Real-World Intrusion Detection System

\section{Discussion on Critical Factors of Successful Implementa- tion}

After implementing the cross-curricular modules over two semesters, we reflected on how to improve the design of the cross-curricular components and identified critical factors that might impact the students' learning. The first factor is 
designing the cross-curricular project based on the connection of the context of two courses and balancing the work between the students from two classes. Students are expected to work together on the project, so, it is better to design a project that has students of both courses contribute their domain knowledge in a relatively equal way. That means students of both classes have the same level of freedom to choose tools or methods in their domain. Based on our current design, the CIT 49900 students have more freedom to choose the machine learning techniques for analyzing the network traffic data, whereas the CIT 45100 students do not have the same level of privilege in determining the network traffic collection tools. The second factor is having students present each others' domain knowledge during the presentation to demonstrate their teamwork and knowledge gained from their peers. In our study, we found that naturally, some students in CIT 45100 would need to present the knowledge of CIT 49900, which they learned from their peers through the project. The students of CIT 49900 asked questions in the network traffic domain, which demonstrates the process of knowledge transfer from one area to another. The last important factor is the arrangement of cross-curricular activities. We implemented this in two semesters. Based on the feedback from the students, they would prefer more in-class collaboration time. That means it would be better to schedule the two courses at a similar time during a semester, so that more than one coursesession can be arranged for students to work on the crosscurricular projects. If more than one course-session is arranged for students to work on the cross-curricular project, care has to be taken to make sure the discipline specific content is also covered. Balancing delivery of cross discipline knowledge and discipline knowledge can be critical.

\section{CONCLUSIONS}

In this research, we investigated two forms of crosscurricular activities on two context-connected courses - big data analytics and IT risk assessment - which are taught in parallel. One is integrated instructional units, and the other is cross-curricular knowledge integration projects. The exampleoriented approach was used to design the integrated units. The knowledge integration projects were designed to make use of the expertise learned from both courses. Interviews and surveys were taken with students to evaluate the success and barriers of cross-curricular activities. Then, qualitative and quantitative analysis were applied to understand the development of students' self-reported skills on their domains (big data analytics or IT risk assessment), as well as connecting knowledge from one domain to another. The results show great improvements in students' confidence in solving crossdisciplinary problems and a much better understanding of data analytics and information security. Most students agree that this cross-curricular setting prepared them better for a future career collaborating with others, and students would like to take more cross-curricular courses. Through this study, we also learned a few critical factors towards better design and implementation of the cross-curricular units and projects. We plan to adopt improved cross-curricular implementation design in the near future.

\section{ACKNOWLEDGMENT}

This work is supported by STEM Education Innovation \& Research Institute of IUPUI.

\section{REFERENCES}

[1] L. D. Fink, Creating significant learning experiences: An integrated approach to designing college courses. John Wiley \& Sons, 2013.

[2] M. Kalantzis and B. Cope, New learning: Elements of a science of education. Cambridge University Press, 2012.

[3] N. R. Council et al., Discipline-based education research: Understanding and improving learning in undergraduate science and engineering. National Academies Press, 2012.

[4] M. K. Smith, W. B. Wood, W. K. Adams, C. Wieman, J. K. Knight, N. Guild, and T. T. Su, "Why peer discussion improves student performance on in-class concept questions," Science, vol. 323, no. 5910, pp. 122-124, 2009.

[5] S. Bates and R. Galloway, "The inverted classroom in a large enrolment introductory physics course: a case study," in Proceedings of the HEA STEM learning and teaching conference, vol. 1, 2012.

[6] L. M. Stearns, J. Morgan, M. M. Capraro, and R. M. Capraro, "A teacher observation instrument for pbl classroom instruction." Journal of STEM Education: Innovations \& Research, vol. 13, no. 3, 2012.

[7] D. Heil, G. Pearson, and S. Burger, "Understanding integrated stem education: Report on a national study," in 120th ASEE Annual Conference \& Exposition, 2013.

[8] C. Tanenbaum, "Stem 2026: A vision for innovation in stem education," US Department of Education, Washington, DC, 2016.

[9] T. J. Moore and K. A. Smith, "Advancing the state of the art of stem integration," Journal of STEM Education: Innovations and Research, vol. 15, no. 1, p. 5, 2014.

[10] M. M. Whiteacre and C. O. Malavé, "An integrated freshman engineering curriculum for pre-calculus students," in FIE'98. 28th Annual Frontiers in Education Conference. Moving from'Teacher Centered'to'Learner-Centered'Education. Conference Proceedings (Cat. No. 98CH36214), vol. 2. IEEE, 1998, pp. 820-823.

[11] N. E. Selinski, C. Rasmussen, M. Wawro, and M. Zandieh, "A method for using adjacency matrices to analyze the connections students make within and between concepts: The case of linear algebra," Journal for Research in Mathematics Education, vol. 45, no. 5, pp. 550-583, 2014.

[12] P. Zenor, J. Fukai, R. Knight, N. Madsen, and J. Rogers, "An interdisciplinary approach to the pre-engineering curriculum," in Proceedings Frontiers in Education 1995 25th Annual Conference. Engineering Education for the 21st Century, vol. 2. IEEE, 1995, pp. 3c1-18.

[13] J. B. Labov, A. H. Reid, and K. R. Yamamoto, "Integrated biology and undergraduate science education: a new biology education for the twenty-first century?" CBE-Life Sciences Education, vol. 9, no. 1, pp. 10-16, 2010.

[14] D. Laboy-Rush, "Integrated stem education through project-based learning," Boston, MA: Learning. com, 2011.

[15] J. Callahan, P. Pyke, S. Shadle, and R. E. Landrum, "Creating a stem identity: Investment with return," 2014.

[16] A. Beckmann, "A conceptual framework for cross-curricular teaching," The Mathematics Enthusiast, vol. 6, no. 4, pp. 1-58, 2009.

[17] J. Kyere, "Effectiveness of hands-on pedagogy in stem education," 2017.

[18] K. Otis, "Top 5-benefits of a hands-on learning environment," Get your medical Assistant training at Everest institute in Norcross, 2010.

[19] R. Rockland, D. S. Bloom, J. Carpinelli, L. Burr-Alexander, L. S. Hirsch, and H. Kimmel, "Advancing the "e" in k-12 stem education," Journal of Technology Studies, vol. 36, no. 1, pp. 53-64, 2010.

[20] J. J. Schwab, "Problems, topics, and issues," Quest, vol. 9, no. 1, pp. 2-27, 1967.

[21] L. Nadelson, L. Walters, and J. Waterman, "Course-integrated undergraduate research experiences structured at different levels of inquiry," Journal of STEM Education: Innovations and Research, 2010. 